\title{
CORRESPONDENCE
}

\section{What are the benefits of medical screening and surveillance?}

\section{To the Editor:}

I read with great interest the recent article by WILKEN et al. [1]. Although the article covers most items, I have queries and suggestions, as well as a comment. 1) The authors focus on high molecular weight agents and propose useful steps for surveillance. However, they say little for sensitisers that are even more common, that is low molecular weight agents for which immunological assessment is not possible. Would the authors suggest regular methacholine testing? We think that methacholine testing should be integrated into a surveillance programme since it can easily be performed in the workplace; the important issue here is comparison with a baseline value obtained preexposure. 2) When, in regards to onset of exposure, and how frequently should surveillance take place? Our group has convincingly shown that sensitisation to high molecular weight agents generally occurs in the first 2 years after the onset of exposure [2,3], which suggests that the first surveillance should be carried out in this interval; also, how often should surveillance be repeated? 3) The authors say that a combination of different tests is preferable but they should say that the most important one is the questionnaire [4], the other means adding very little. 4) We appreciate the distinction made by the authors between medical screening and surveillance; however, in our region of the world, "screening" (in French, "dépistage") bears a rather negative interpretation, particularly for trade unions that fear that employees can be excluded from workplaces. This is the reason that we prefer to propose medical surveillance programmes.

\section{Jean-Luc Malo}

Hôpital du Sacré-Coeur de Montréal, Montreal, Canada.

Correspondence: J-L Malo, Hôpital du Sacré-Coeur de Montréal, 5400 West Gouin Blvd, Montreal, H4J 1C5, Canada. E-mail: malojl@meddir.umontreal.ca

Statement of Interest: None declared.

Provenance: Submitted article, peer reviewed.

\section{REFERENCES}

1 Wilken D, Baur X, Barbinova L, et al. What are the benefits of medical screening and surveillance? Eur Respir Rev 2012; 21: 105-111.

2 Gautrin D, Infante-Rivard C, Ghezzo H, et al. Incidence and host determinants of probable occupational asthma in apprentices exposed to laboratory animals. Am J Respir Crit Care Med 2001; 163: 899-904.

3 Gautrin D, Ghezzo H, Infante-Rivard C, et al. Long-term outcomes in a prospective cohort of apprentices exposed to high-molecularweight agents. Am J Respir Crit Care Med 2008; 177: 871-879.
4 Suarthana E, Malo J-L, Heederik D, et al. Which tools best predict the incidence of work-related sensitisation and symptoms. Occup Environ Med 2008; 66: 111-117.

DOI: $10.1183 / 09059180.00004212$

\section{From the authors:}

We appreciate J-L. Malo's comments drawing attention to the surveillance of workers exposed to airborne allergens or irritants and at risk of developing allergy and asthma. It identifies some relevant gaps in the existing knowledge as presented in our recent publication [1] and underlines the need for further research.

Our document gives an overview of the existing evidence regarding surveillance of populations at risk of developing occupational asthma and includes a critical evaluation of that evidence. Indeed, the procedures and steps for surveillance in workers exposed to low molecular weight agents have not been addressed explicitly. In general, surveillance should include a combination of tests, preferably administered periodically from the start of exposure onwards. Nonspecific bronchial hyperresponsiveness (NSBHR) is suggested as a useful component of surveillance for workers exposed to high and low molecular weight agents [1]. In the absence of a valid test for sensitisation, as in the case of many low molecular weight sensitisers, NSBHR will receive a more prominent place in surveillance. However, NSBHR testing in the workplace is a demanding fine-diagnostic tool, both from the perspective of quality and safety [2,3]; according to our experience, it is rarely possible to apply NSBHR tests as part of routine surveillance investigations in occupational health practice.

NSBHR testing is a more invasive method than, for example, skin-prick testing (SPT), especially in a surveillance setting. Risk stratification could be advantageous because it could reduce the number of tests. Symptoms and NSBHR are frequently associated but absence of NSBHR in affected workers has also been repeatedly reported [4-8]. Furthermore, multivariate diagnostic rules for NSBHR are lacking and need to be developed on the basis of larger studies.

As far as we know, the optimal interval between tests of the surveillance programme in terms of cost-effectiveness has not yet been subject to study. Although the increased risk of sensitisation during the first years after the onset of exposure may justify shorter intervals during that period, other factors should also be taken into account, such as the potency of the irritant agent to cause work-related asthma as well as of the allergen to induce sensitisation, individual susceptibility factors, the wide range of latency periods (sometimes $>10 \mathrm{yrs}$ ) and the level of exposures or control measures. Thus, the individual workplace situation will usually necessitate a specific surveillance programme. For more detail, see some of the publications available on this topic $[9,10]$. 
We strongly encourage more detailed investigations in order to gain more evidence for such promising approaches.

Indeed, the basis of surveillance is the questionnaire, which is emphasised in statement 9 in our article as well as in the first recommendation [1]. SPT or specific immunoglobulin E measurements are minimally invasive techniques, and sensitisation to occupational high molecular weight allergens is strongly associated with work-related allergy. A pragmatic approach is, first, to identify sensitised subjects, followed by more burdensome tests in high-risk groups or doubtful cases [11]. The costbenefit for the worker is clear [12]. The relationship between test outcome, work-related symptoms and allergy or asthma is usually strong. Diagnostic rules that make use of multiple test outcomes have been suggested to limit the number of workers that needs to be subjected to these tests by risk stratification [10].

We agree with point 4 of J-L. Malo's correspondence; for that reason, the difference between screening and surveillance has been stipulated, with emphasis on surveillance as a comprehensive prevention strategy.

\section{Xaver Baur*, Dennis Wilken*, Jos Rooyackers" and Dick Heederik"}

*Institute for Occupational and Maritime Medicine, University Medical Center Hamburg-Eppendorf, Hamburg, Germany. \#Netherlands Expertise Center for Occupational Respiratory Disorders - NECORD IRAS NKAL, and "Enviromental Epidemiology Division, Institute for Risk Assessment Sciences (IRAS), University of Utrecht, Utrecht, The Netherlands.

Correspondence: X. Baur, Institute for Occupational Medicine and Maritime Medicine, University Hospital HamburgEppendorf, Seewartenstr. 10, D-20459, Hamburg, Germany. E-mail: xaver.baur@bgv.hamburg.de

Statement of Interest: None declared.

Provenance: Submitted article, peer reviewed.

\section{REFERENCES}

1 Wilken D, Baur X, Barbinova L, et al. What are the benefits of medical screening and surveillance? Eur Respir Rev 2012; 21: 105-111.

2 Crapo RO, Casaburi R, Coates AL, et al. Guidelines for methacholine and exercise challenge testing-1999. This official statement of the American Thoracic Society was adopted by the ATS Board of Directors, July 1999. Am J Respir Crit Care Med 2000; 161: 309-329.

3 Sterk PJ, Fabbri LM, Quanjer PH, et al. Airway responsiveness. Standardized challenge testing with pharmacological, physical and sensitizing stimuli in adults. Report Working Party Standardization of Lung Function Tests, European Community for Steel and Coal. Official Statement of the European Respiratory Society. Eur Respir J 1993; 6: Suppl. 16, 53-83.

4 Anees W, Huggins V, Pavord ID, et al. Occupational asthma due to low molecular weight agents: eosinophilic and non-eosinophilic variants. Thorax 2002; 57: 231-236.

5 Baur X, Huber H, Degens PO, et al. Relation between occupational asthma case history, bronchial methacholine challenge, and specific challenge test in patients with suspected occupational asthma. Am I Ind Med 1998; 33: 114-122.

6 Brisman J, Lillienberg L, Belin L, et al. Sensitisation to occupational allergens in bakers' asthma and rhinitis: a case-referent study. Int Arch Occup Environ Health 2003; 76: 167-170.

7 Hargreave FE, Ramsdale EH, Pugsley SO. Occupational asthma without bronchial hyperresponsiveness. Am Rev Respir Dis 1984; 130: 513-515.

8 Vandenplas O, Binard-Van Cangh F, Brumagne A, et al. Occupational asthma in symptomatic workers exposed to natural rubber latex: evaluation of diagnostic procedures. I Allergy Clin Immunol 2001; 107: 542-547.

9 Gautrin D, Ghezzo H, Infante-Rivard C, et al. Natural history of sensitization, symptoms and occupational diseases in apprentices exposed to laboratory animals. Eur Respir J 2001; 17: 904-908.

10 Meijer E, Suarthana E, Rooijacker J, et al. Application of a prediction model for work-related sensitisation in bakery workers. Eur Respir J 2010; 36: 735-742.

11 Suarthana E, Meijer E, Grobbee DE, et al. Predicting occupational diseases. Occup Environ Med 2009; 66: 713-714.

12 Suarthana E, Vergouwe $Y$, Moons KG, et al. A diagnostic model for the detection of sensitization to wheat allergens was developed and validated in bakery workers. J Clin Epidemiol 2010; 63: 1011-1019.

DOI: $10.1183 / 09059180.00004412$ 